Konservasi Hayati, 17 (2): 85-92, Oktober (2021)

https://ejournal.unib.ac.id/index.php/hayati/

p-ISSN: 0216-9487

email:konservasihayati@unib.ac.id

e-ISSN: 2722-1113

\title{
KEANEKARAGAMAN TERIPANG (Holothuroidae) di ZONA INTERTIDAL PADA AREA KONSERVASI "SASI" KAMPUNG FOLLEY DISTRIK MISOOL TIMUR KABUPATEN RAJA AMPAT - PAPUA BARAT
}

\author{
Marice B. Moom ${ }^{1}$, Vera Sabariah ${ }^{* 1,2}$, Tutik Handayani ${ }^{1}$, Abdul H.A. Toha ${ }^{1}$ \\ Fanny F.C. Simatauw ${ }^{1}$, Selvi Tebay ${ }^{1}$, Fitryah I. Saleh ${ }^{1}$ \\ ${ }^{1}$ Fakultas Perikanan dan Ilmu Kelautan Universitas Papua \\ ${ }^{2}$ Program Pascasarjana Universitas Papua \\ * corresponding author: vsabariah@gmail.com
}

\begin{abstract}
Sasi can be defined as a 'prohibition' to take natural resources in a coastal area outside the specified time. This study aimed to analyze species abundance and diversity of sea cucumber (Holothuroidae) in the area applying the sasi at Kampung Folley District Misool Timur, Raja Ampat Regency. Study was done at Tanjung Vageta dan Tanjung Waponta that applied sasi, andl site in the outer area sasi which is Dermaga Kampung Folley as a comparison. Data was collected from June-July 2019 by survey method with a line transect $100 \mathrm{~m}$ along the coastline. Results found that 7 sea cucumber species in "sasi" area were Holothuria scabra, H. edulis, H. atra, H. leucuspilota, H. impatiens, Stichopus hermanii, and Synapta maculata. H. scabrawas is mostly found in the sasi conservancy area as well as the species is important to the local community.
\end{abstract}

Keywords: Holothuroidea, Raja Ampat, sasi, sea cucumber

\begin{abstract}
ABSTRAK
Sasi dapat didefinisikan sebagai suatu 'larangan' untuk mengambil sumber daya alam di kawasan pesisir di luar waktu yang ditentukan. Penelitian ini bertujuan untuk mengkaji keanekaragaman teripang (Holothuroidae) pada kawasan yang melakukan kebijakan sasi di Kampung Folley Distrik Misool Timur Kabupaten Raja Ampat, Papua. Penelitian dilakukan di perairan Tanjung Vageta dan Tanjung Waponta yang menerapkan kebijakan sasi, serta 1 lokasi di luar area sasi yaitu Perairan Dermaga Kampung Folley sebagai pembanding. Pengambilan data dilakukan dari Juni sampai Juli 2019 menggunakan metode survey dengan transek sepanjang $100 \mathrm{~m}$ sejajar garis pantai. Penelitian mendapatkan tujuh jenis teripang di lokasi konservasi sasi yakni Holothuria scabra, H. edulis, H. atra, H. leucuspilota, H. impatiens, Stichopus hermanii, Synapta maculata.Teripang $H$. Scabra memiliki populasi terbanyak di area konservasi sasi dan merupakan komoditas penting bagi masyarakat lokal.
\end{abstract}

Kata Kunci: Holothuroidea, Raja Ampat, sasi, teripang

\section{PENDAHULUAN}

Kepulauan Raja Ampat, yang menjadi bagian Provinsi Papua, berada di Segi tiga Terumbu Karang yang diakui sebagai pusat keanekaragaman hayati laut dunia. Kawasan Raja Ampat merupakan rumah bagi 553 jenis terumbu karang $(75 \%$ dari total jenis di dunia) dan 1.437 jenis ikan karang (Bentang Laut Kepala Burung, 2012). Kawasan konservasi perairan di Raja Ampat dikelola melalui sistem zonasi untuk mewujudkan manajemen sumber daya perairan dan lingkungan yang berkelanjutan. Pada tahun 2006, pemerintah daerah Kabupaten Raja Ampat, bersama dengan masyarakat lokal, The Nature 
Conservancy dan Conservation International Indonesia Programme, mendeklarasikan berdirinya jejaring Kawasan Konservasi Laut Daerah (KKLD), diantaranya bertujuan untuk menopang perikanan laut yang berkelanjutan.

Kampung Folley di Distrik Misool Timur merupakan bagian dari Kabupaten Raja Ampat yang selain dilindungi oleh kebijakan konservasi pemerintah, memiliki kearifan lokal yang dinamakan dengan "sasi". Kearifan lokal "sasi" melarang untuk mengeksploitasi teripang di kampung Folley pada waktu tertentu sampai saatnya akan dipanen atau dikenal sebagai "buka sasi". Kebijakan sasi teripang di Kampung ini mulai diberlakukan pada tahun 2012 dan panen pertama pada tahun 2013 (Mongabay, 2013). Di kampung Folley, sasi diberlakukan untuk teripang tapi di tempat lain juga berlaku untuk biota laut lainnya (Pemda Kabupaten Raja Ampat, 2006).

Teripang adalah biota makrozoobenthos yang dapat ditemukan hampir di seluruh perairan pantai, mulai dari daerah pasang surut yang dangkal sampai perairan yang dalam. Menurut Clark dan Rowe (1971), ada sekitar 53 jenis teripang dari genera Holothuria, Actinophyga, Bohadschia, Labiodemas, Thelonata dan Stichopus yang terdapat di perairan Indonesia. Sekitar 1200 jenis teripang yang ada di dunia, saat ini sekitar 5\% berada di Indonesia dan dari jumlah tersebut dipastikan ada 7 jenis yang tergolong mempunyai nilai jual yang tinggi yakni teripang pasir (H. scabra), teripang hitam (H. edulis), teripang coklat ( $H$. marmoreta), teripang merah $(H$. vatiensis), teripang koro (H. nobilis), teripang nanas (T. ananas), dan teripang gamat ( $S$. varigatus), (Clark dan Rowe, 1971). Teripang berperan penting sebagai pemakan deposit dan pemakan suspensi. Hewan ini mencerna sejumlah besar sedimen, yang memungkinkan terjadinya oksigenasi pada lapisan atas sedimen.

Mongabay (2013) melaporkan sasi teripang yang dilakukan pada tahun tersebut di Misool menghasilkan 1338 ekor teripang. Tetapi dari pengamatan langsung yang dilakukan saat sekarang ini, belum diketahui keberadaan dan kelimpahan sumber daya teripang di lokasi tersebut. Oleh karenanya, penelitian ini bertujuan untuk mengetahui (1) jenis dan kelimpahan teripang, serta (2) keanekaragaman dan dominansi jenis teripang pada perairan laut yang dilindungi dengan "sasi" di Kampung Folley Distrik Misool Timur Kabupaten Raja Ampat Papua.

\section{METODE \\ Waktu dan Tempat}

Pengambilan data untuk penelitian ini dilakukan dari Juni sampai dengan Juli 2019. Lokasi penelitian berada pada zona intertidal perairan sekitar Kampung Folley, Distrik Misool Timur, Kabupaten Raja Ampat, Papua yang dilindungi dengan sasi (koordinat $1^{\circ}$ 53'41'S dan $130^{\circ}$ 5'1'"E) (Gambar 1).

\section{Alat dan Bahan}

Alat yang digunakan dalam penelitian adalah transek kuadran $5 \times 5$ m, rol meter, alat tulis, GPS, termometer, refraktometer, DO meter, tali, kamera serta buku identifikasi teripang (Commercially Important Sea Cucumbers of The World 2012 dan Pedoman umum Identifikasi dan Monitoring, Populasi Teripang, 2015). Bahan yang dipakai untuk penelitian adalah sampel teripang. 
Konservasi Hayati, 17 (2): 85-92, Oktober (2021)

https://ejournal.unib.ac.id/index.php/hayati/
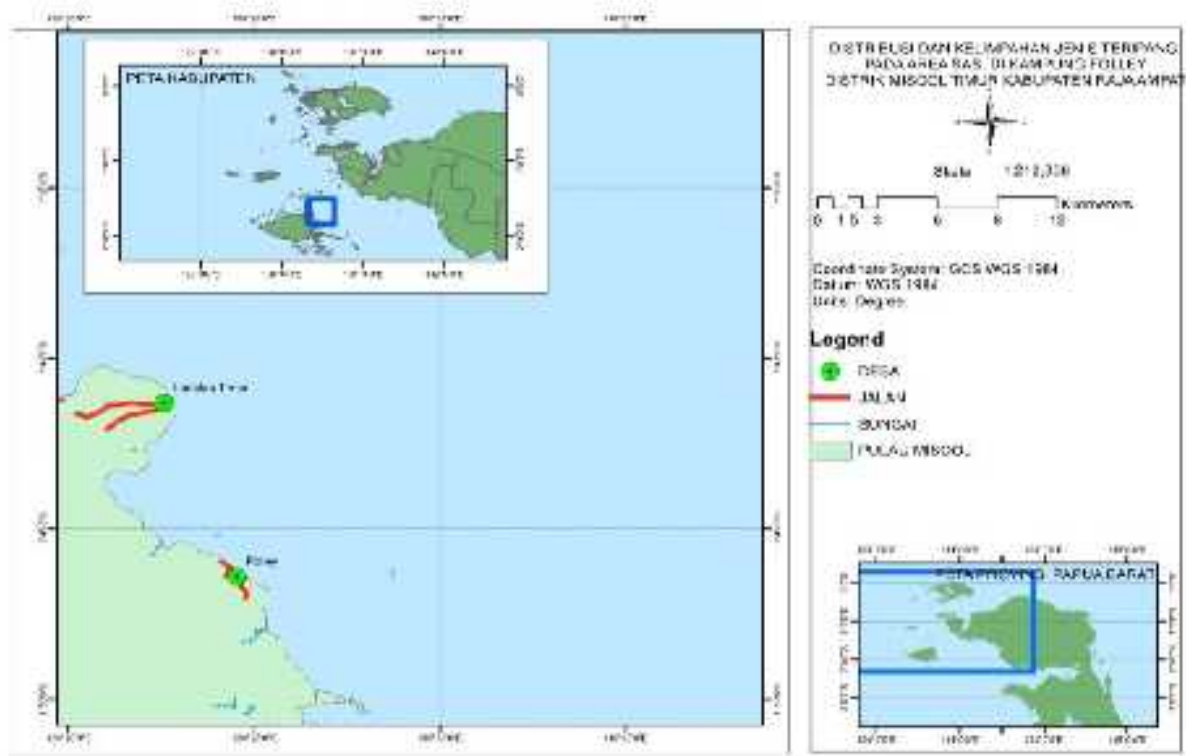

Gambar 1. Letak Kampung Folley Distrik Misool Timur

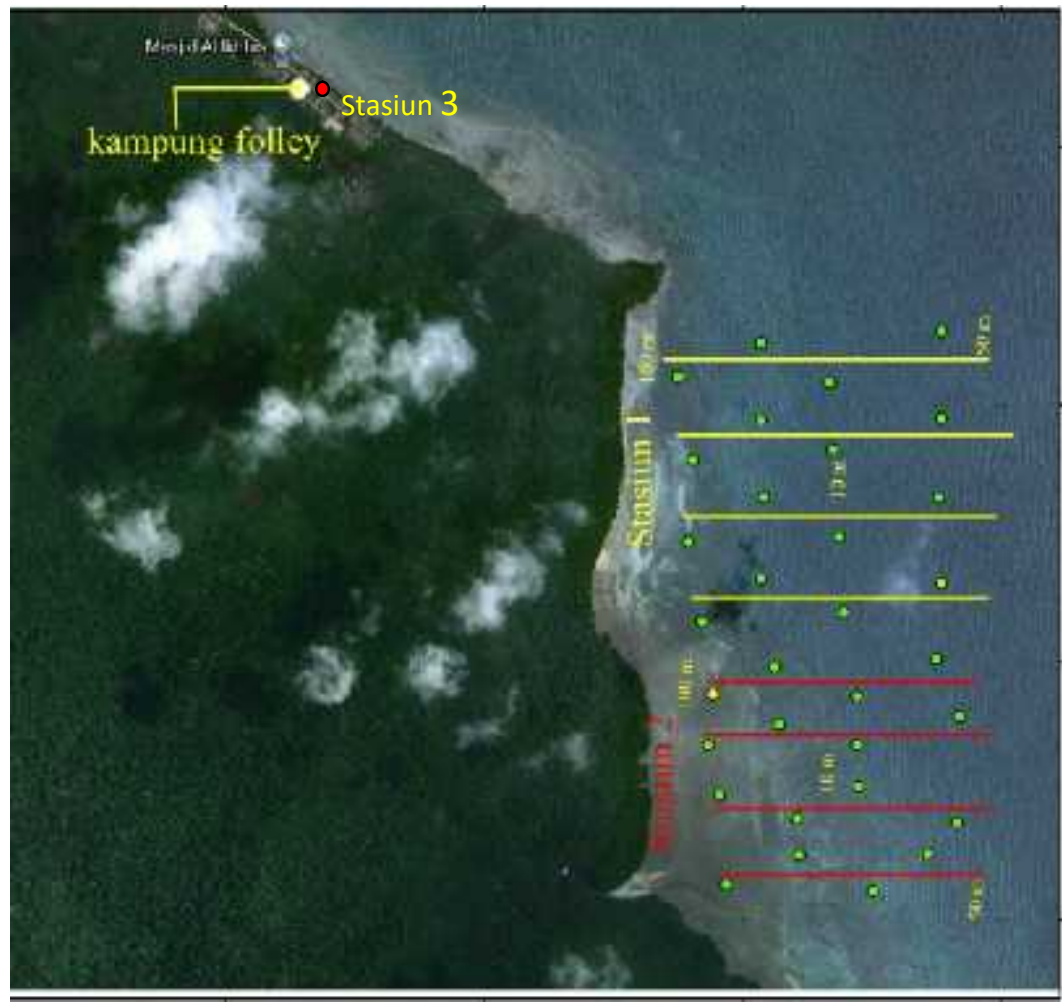

Gambar 2. Sketsa peletakan line transek di lokasi penelitian

\section{METODE}

Teripang dikoleksi melalui survei secara langsung di mana titik pengambilan sampel ditentukan secara purposif. Pengambilan sampel pada kawasan yang dilindungi sasi dilakukan pada stasiun 1 di Tanjung Vageta dan stasiun 2 di Tanjung Woponta. Sampel teripang dari kawasan yang tidak dilindungi sasi diambil dari stasiun 3 di Dermaga Kampung Folley, tetapi tidak diperoleh karena merupakan tempat lalu lintas perahu nelayan. Jarak antara setiap stasiun ini $1 \mathrm{Km}$. Interval pengambilan sampel yaitu $5 \mathrm{~m}$ dari bibir pantai ke arah laut secara horizontal 20m (Gambar 2). 
Sampel teripang dikoleksi di sepanjang $100 \mathrm{~m}$ transek dari garis pantai menuju ke arah laut pada saat pasang surut, dan menggunakan empat buah kuadran ukuran $5 \times 5 \mathrm{~m}^{2}$ yang diletakkan secara zig-zag di sepanjang transek. Setiap stasiun terdiri dari 4 transek. Teripang yang ditemukan di setiap kuadran diambil secara langsung menggunakan tangan. Identifikasi jenis dilakukan menggunakan ciri morfologi (bentuk dan warna).

Pengukuran data lingkungan perairan dilakukan bersamaan dengan pengambilan sampel teripang, meliputi jenis substrat, suhu, $\mathrm{pH}$, kadar salinitas dan oksigen terlarut dan pengamatan jenis substrat.

\section{Analisa Data}

Jenis teripang dan jumlah populasi per masing-masing jenis dihitung sesuai dengan hasil identifikasi sampel yang dikoleksi di lapangan. Sedangkan kelimpahan relatif, keanekaragaman jenis dan dominansi jenis teripang dihitung berdasarkan rumus ekologi (Odum, 1998) berikut:

$K R=\frac{n i}{\mathrm{~N}} \times 100 \%$

$\mathrm{H}^{\prime}=\Sigma \mathrm{Pi} \log _{2} \mathrm{Pi}$, dengan $\mathrm{Pi}=\frac{u i}{N}$

$c=\sum_{i=1}^{n} p^{2} i=\sum_{i=1}^{n}\left[\left(\frac{n i}{N}\right)^{\pi}\right.$

Untuk kelimpahan relative $(\mathrm{KR}), \mathrm{ni}=$ jumlah individu spesies ke-i, dan $\mathrm{N}=$ Jumlah total individu seluruh jenis. Indeks Keanekaragaman Spesies dimana H' = indeks keanekaragaman Shannon-Wienner, ni $=$ jumlah individu satu jenis, $\mathrm{N}=$ jumlah individu seluruh jenis. Dengan kriteria: $\mathrm{H}^{\prime} \leq$ 1,0 keanekaragaman rendah, $1,0 \leq \mathrm{H}^{\prime} \leq 3,0$ keanekaragaman sedang, dan $\mathrm{H}^{\prime} \geq 3,0$ : keanekaragaman tinggi (Fachrul, 2017). Indeks Dominansi $(=\mathrm{C})$, dimana ni $=$ Jumlah individu ke-i dan $\mathrm{N}=$ Jumlah total individu. Nilai Indeks Dominansi dikelompokkan dalam tiga kriteria, yaitu $0<\mathrm{C} \leq 0,5=$ Dominasi rendah0,5 $<\mathrm{C} \leq 0,7=$ Dominasi sedang, dan $0,75<\mathrm{C} \leq 1=$ Dominasi tinggi.
Pola penyebaran teripang di lokasi penelitian dihitung menggunakan Indeks Morisita (Soegianto, 1994) dengan persamaan sebagai berikut:

$$
\mathrm{Id}=\mathrm{n} \frac{2 \mathrm{x}^{2}}{(\mathrm{~N}-\mathrm{I})}
$$

Dimana Id $=$ Indeks Distribusi spesies, $\mathrm{n}=$ jumlah plot, $\mathrm{N}=$ jumlah total individu yang diperoleh, $\Sigma \mathrm{x}^{2}=$ perkalian jumlah spesies pada setiap plot (x) dan frekuensi ditemukan dalam jumlah plot $\mathrm{f}(\mathrm{x})$, dengan kriteria: $\mathrm{Id}=1$, Pola penyebaran bersifat acak, Id $<1$, Pola penyebaran seragam, Id $>1$, Pola penyebaran secara mengelompok.

\section{HASIL DAN PEMBAHASAN \\ Jenis dan Populasi Teripang (Holothuroidae) di Kawasan Penelitian}

Terdapat tujuh jenis teripang yang ditemukan pada area sasi Kampung Follay, yaitu $H$. scabra, H. leuscupilota, H. atra, $H$. edulis, S. hermanii, S. maculata, dan $H$. impatiens. Jumlah individu teripang terbanyak ditemukan di stasiun 1 yang habitatnya berupa paparan padang lamun dan jumlah individu sebesar 254 individu dan pada stasiun 2 terdapat 126 individu teripang (Tabel 1). Conservation International Indonesia (2013) melaporkan terdapat 19 jenis teripang dari kawasan perairan Misool, Raja Ampat. Perbedaan jumlah jenis dengan penelitian yang dilakukan sekarang diduga dari perbedaan luas daerah penelitian dan kedalaman kawasan sampling.

Tabel 1. Jenis, jumlah teripang yang ditemukan di lokasi penelitian

\begin{tabular}{lcc}
\hline \multicolumn{1}{r}{ Jenis teripang } & Stasiun & Stasiun \\
& $\mathbf{1}$ & $\mathbf{2}$ \\
\hline H. atra & 11 & 0 \\
H.edulis & 2 & 2 \\
H.impatiens & 0 & 1 \\
H. leuscuspilota & 83 & 27 \\
H.scabra & 141 & 95 \\
S. hermanii & 0 & 1 \\
S. maculata & 15 & 0 \\
\hline \multicolumn{1}{r}{ Jumlah } & $\mathbf{2 5 2}$ & $\mathbf{1 2 6}$ \\
\hline
\end{tabular}


Pada stasiun 3 tidak ditemukan individu teripang. Stasiun tersebut berada dekat dengan kawasan permukiman dan tidak termasuk dalam area sasi.

\section{Kelimpahan Relatif, Keanekaragaman dan Dominansi Teripang}

Teripang $H$. scabra adalah yang tertinggi kelimpahannya $(\mathrm{KR}=55,95 \%)$ untuk di stasiun 2 di dalam area sasi, diikuti oleh teripang $H$. Leucuspilota $(\mathrm{KR}=32,94 \%)$, sementara teripang jenis lain memiliki kelimpahan rendah $(\mathrm{KR}<10 \%$, Tabel 2).
Kelimpahan teripang H. scabra di kawasan sasi kemungkinan didukung oleh substrat di kawasan ini yang berupa pasir halus berlumpur, dengan karang dan lamun yang disukai oleh teripang. Habitat berlamun dapat berfungsi sebagai pelindung dan perangkap makanan bagi teripang. Selain itu, padang lamun dan karang menyediakan habitat bagi teripang untuk berlindung dari sinar matahari (Sabariah et al, 2011). Ini dinyatakan juga oleh Handayani et al, (2017) bahwa kelimpahan teripang berkaitan dengan substrat perairan.

Tabel 2. Kelimpahan relatif (KR), Keanekaragaman dan Dominansi teripang

\begin{tabular}{lcccccc}
\hline \multirow{2}{*}{ Jenis teripang } & \multicolumn{2}{c}{ KR (\%) } & \multicolumn{2}{c}{ Keanekaragaman } & \multicolumn{2}{c}{ Dominansi } \\
\cline { 2 - 7 } & Stasiun 1 & Stasiun 2 & Stasiun 1 & Stasiun 2 & Stasiun 1 & Stasiun 2 \\
\hline H. atra & 4,37 & 0,00 & 0,06 & 0,00 & 0,00 & 0,00 \\
H. edulis & 0,79 & 1,59 & 0,02 & 0,03 & 0,00 & 0,00 \\
H. impatiens & 0,00 & 0,79 & 0,00 & 0,02 & 0,00 & 0,00 \\
H. leuscuspilota & 32,94 & 21,43 & 0,11 & 0,14 & 0,11 & 0,08 \\
H. scabra & 55,95 & 75,40 & 0,14 & 0,09 & 0,31 & 0,39 \\
S. hermanii & 0,00 & 0,79 & 0,00 & 0,02 & 0,00 & 0,00 \\
S. maculata & 5,95 & 0,00 & 0,07 & 0,00 & 0,00 & 0,00 \\
\hline \multicolumn{1}{c}{ Total } & & & $\mathbf{0 , 4 2}$ & $\mathbf{0 , 3 0}$ & $\mathbf{0 , 4 3}$ & $\mathbf{0 , 6 1}$ \\
\hline \multicolumn{1}{c}{} & & & &
\end{tabular}

Meskipun ketujuh jenis teripang yang ditemukan dalam penelitian ini terdapat pada kedua kawasan sasi di Tanjung Vageta dan Tanjung Woponta, tetapi keragaman jenis totalnya terhitung rendah $\left(\mathrm{H}^{\prime}=0,30\right.$ sampai 0,42, Tabel 4). Penelitian serupa di kawasan sasi di perairan Numfor, Papua menemukan hanya dua jenis teripang dengan keragaman jenis yang juga rendah, sedangkan di kawasan luar sasi terdapat keragaman teripang kategori sedang (Baransano, et al., 2019).

Rendahnya keanekaragaman teripang di lokasi penelitian diduga disebabkan kegiatan panen teripang yang dilakukan sebelum berlangsungnya penelitian ini (komunikasi langsung dengan masyarakat setempat). Nurafni et al. (2020) menyatakan Indeks Keanekaragaman pada suatu komunitas juga ditentukan oleh banyaknya jenis dan jumlah individu jenis. Keanekaragaman spesies dapat digunakan juga untuk mengukur stabilitas komunitas di ekosistem, yaitu kemampuan suatu komunitas agar tetap stabil meskipun ada gangguan terhadap komponen lingkungannya (Solikhatun et al., 2019; Doudi, 2020).

Dominansi suatu jenis yang besar komunitas tempat jenis tersebut hidup. Komunitas teripang di perairan Kampung Folley tidak didominasi oleh suatu jenis tertentu $(\mathrm{C}<0,61)$ (Tabel 2). Dengan kata lain komunitas teripang di lokasi penelitian masih berada dalam kondisi stabil atau belum teramati adanya tekanan ekologis.

Upaya pelestarian sumber daya alam di laut melalui sasi (hukum adat) sejak tahun 2011 yang dilembagakan di Misool, saat ini telah memperlihatkan hasilnya bagi masyarakat khususnya di kampung Folley. Terjaganya terumbu karang, membuat ikanikan dan biota perairan lainnya di kawasan perairan ini dapat berkembang biak dengan baik. Mongabay (2013) menyebutkan bahwa panen teripang pada bulan Juni 2013 dalam pembukaan sasi perdana (melalui adat dan gereja),masyarakat kampung Misool memanen teripang senilai 50 juta rupiah dalam 4 hari dari lokasi seluas 82 hektar. Hasil tangkapan 
masyarakat selama buka sasi untuk teripang saat itu mencapai 1.338 ekor dengan ukuran panjang berkisar $15-20 \mathrm{~cm}$. Selama sasi tersebut dibuka, tercatat ada 20 nelayan yang memanen selama 4 hari dengan rata-rata tangkapan berkisar 67 ekor teripang/hari.

\section{Pola Sebaran Teripang di Perairan Kampung Folley}

Data penelitian mengindikasikan bahwa baik pada Tanjung Vageta atau Tanjung Woponta, teripang tersebar secara mengelom- pok $(2,10<\mathrm{Id}<2,76$; lihat Tabel 3). Pola penyebaran mengelompok pada teripang ini menunjukkan adaptasi yang baik dengan kondisi lingkungan perairannya masingmasing. Teripang H. Scabra memiliki indeks penyebaran yang paling besar $(\mathrm{Id}=1,64)$, berarti jenis ini yang paling baik teradaptasi dengan lingkungannya. Pola penyebaran mengelompok pada teripang ini diduga sebagai upaya untuk saling melindungi, terutama dari hewan predator (Martoyo, 2007).

Tabel 3. Pola sebaran teripang di perairan Kampung Folley

\begin{tabular}{lcccc}
\hline \multirow{2}{*}{ Jenis Teripang } & \multicolumn{2}{c}{ Tanjung Vageta } & \multicolumn{2}{c}{ Tanjung Woponta } \\
\cline { 2 - 5 } & ind & Id & ind & Id \\
\hline Holothuria atra & 11 & 0,30 & 0 & 0,00 \\
Holothuria edulis & 2 & 0,05 & 2 & 0,10 \\
Holothuria impatiens & 0 & 0,00 & 1 & 0,10 \\
Holothuria leuscuspilota & 83 & 0,60 & 27 & 0,82 \\
Holothuria scabra & 141 & 0,80 & 95 & 1,64 \\
Stichopus hermanii & 0 & 0,00 & 1 & 0,10 \\
Synapta maculata & 15 & 0,35 & 0 & 0,00 \\
\hline \multicolumn{1}{c}{ Total } & $\mathbf{2 5 2}$ & $\mathbf{2 , 1 0}$ & $\mathbf{1 2 6}$ & $\mathbf{2 , 7 6}$ \\
\hline \multicolumn{1}{c}{} & & & &
\end{tabular}

Pola sebaran mengelompok pada teripang juga ditemukan di perairan Morotai, Maluku Utara (Nurfani et al., 2020). Pola penyebaran teripang ini dipengaruhi oleh kondisi lingkungan yang berhubungan dengan daya adaptasi dari masing-masing jenisnya. Selain itu, ketersediaan makanan, perlindungan terhadap predator maupun arus dan gelombang ikut memberikan pengaruh, tidak hanya pada persebaran populasi suatu organisme, tetapi juga terhadap pertumbuhan dan kondisi lebih lanjutnya di dalam habitat perairan (Sarmawati et al., 2016). Sebaran mengelompok pada teripang dapat juga dikaitkan dengan pola distribusi habitat biota lainnya (Hartomas, 2000).

\section{Faktor Lingkungan di Kawasan Penelitian}

Kondisi lingkungan perairan di kawasan penelitian secara rata-rata dari dua pengukuran yang dilakukan di tiap lokasi masih memenuhi baku mutu air laut (Keputusan Menteri Lingkungan Hidup Nomor 51 Tahun 2004). Bahkan untuk oksigen terlarut berkisar 10,78 $\mathrm{mg} / \mathrm{l}$ (Tabel 4) di lokasi penelitian atau $>5 \mathrm{mg} / \mathrm{L}$ yang tercantum pada Baku Mutu Air Laut untuk kehidupan biota air.

Tabel 4. Parameter Kualitas Air di Lokasi Penelitian

\begin{tabular}{|c|c|c|c|c|c|}
\hline Parameter & Pengukuran & Stasiun 1 & Stasiun 2 & Stasiun 3 & Rata-rata \\
\hline \multirow[t]{2}{*}{ Suhu $\left({ }^{\circ} \mathrm{C}\right)$} & 1 & 26,50 & 26,50 & 27,90 & \\
\hline & 2 & 26,70 & 26,70 & 27,90 & 27,03 \\
\hline \multirow[t]{2}{*}{ Salinitas (o/oo) } & 1 & 26,00 & 26,00 & 27,00 & \\
\hline & 2 & 27,00 & 27,00 & 27,00 & 26,67 \\
\hline \multirow[t]{2}{*}{$\mathrm{pH}$} & 1 & 7,79 & 7,67 & 8,60 & \\
\hline & 2 & 7,78 & 7,78 & 8,80 & 8,07 \\
\hline \multirow[t]{2}{*}{$\mathrm{DO}(\mathrm{mg} / \mathrm{L})$} & 1 & 10,40 & 10,10 & 12,00 & \\
\hline & 2 & 10,20 & 10,00 & 12,00 & 10,78 \\
\hline
\end{tabular}


Konservasi Hayati, 17 (2): 85-92, Oktober (2021)

https://ejournal.unib.ac.id/index.php/hayati/

p-ISSN: 0216-9487

email:konservasihayati@unib.ac.id

e-ISSN: 2722-1113

Tabel 5. Jenis substrat

\begin{tabular}{lccc}
\hline \multicolumn{1}{c}{ Jenis Substrat } & Stasiun 1 & $\begin{array}{c}\text { Stasiu } \\
\text { n II }\end{array}$ & $\begin{array}{c}\text { Stasiun } \\
\text { III }\end{array}$ \\
\hline Pasir Halus & + & + & + \\
Pasir Berlumpur & + & + & - \\
Pecahan Karang & + & + & - \\
Pasir Dengan Lamun & + & + & + \\
\hline
\end{tabular}

Keterangan : (+) ada, (-) tidak ada

Meskipun di Stasiun 3 yang berada di luar area sasi memiliki parameter kualitas air yang hampir sama dengan kedua stasiun penelitian, tetapi tidak ditemukan teripang diduga karena aktivitas masyarakat banyak dilakukan di lokasi tersebut karena merupakan tempat tambatan perahu dan dermaga di Kampung. Jenis substrat yang ada di stasiun 3 juga hanya terdiri dari pasir halus dan pasir dengan lamun (Tabel 5).

\section{PENUTUP}

Jenis teripang yang ditemukan di perairan Kampung Folley Distrik Misool Timur Kabupaten Raja Ampat tercatat sebanyak tujuh jenis, yaitu $H$. scabra, $H$. leucuspilota, H. atra, $H$. edulis $H$. impatiens, Stichopus shermanii dan Synapta maculata. Jumlah individu yang ditemukan sebanyak 378 ekor, dengan kelimpahan relatif tertinggi adalah teripang $H$. scabra pada stasiun II Tanjung Woponta. Indeks Keanekaragaman teripang rendah karena adanya kegiatan pemanenan oleh penduduk sebelum pengambilan sampel dilakukan. Komunitas teripang yang ada di perairan ini terindikasi stabil, pola distribusi teripang mengelompok, yang merupakan bentuk adaptasinya dengan kondisi lingkungan.

\section{DAFTAR PUSTAKA}

Baransano N., Dimara, L., Menufandu, H. (2019). Kelimpahan dan Keanekaragaman Teripang Pada Daerah Sasisen dan Non-Sasisen di Perairan

Pulau Numfor. Jurnal Acropora Vol. 2 (1): 8-14.

Bentang Laut Kepala Burung. (2012). Conservation International and The Nature Conservancy and Fact sheet https://birdsheadseascape.com/wpcontent/uploads/Factsheet_RajaAmpat_2012_Indo.pdf

Clark, A.M., Rowe. F.W.E. (1971). Monograph of Shallow Water Indo-west Pacific Echinoderms. London, Trustees of British Museum : 171-210.

Doudi, M., Rasnovi, S., Dahlan. (2020). Keanekaragaman Vegetasi di Kawasan Geotermal Gunung Seulawah Agam Kabupaten Aceh Besar. Prosiding Seminar Nasional Biotik 2020. UIN ArRaniry, Aceh. 22 Juni 2020.

Fachrul. M.F. (2007). Metode Sampling Bioekologi. Bumi Aksara. Jakarta.

Handayani, T., Sabariah, V., Hambuako, R.R. (2017). Komposisi spesies teripang (Holothuroidea) di perairan Kampung Kapisawar Distrik Meos Manswar Kabupaten Raja Ampat. Jurnal Perikanan Universitas Gadjah Mada, 19 (1): 45-51.

Hartomas, K. (2000). Beberapa parameter Fisika dan Kimia Perairan yang Mempengaruhi Kelimpahan dan Distribusi Berbagai Jenis Teripang Holothuria scabra pada Habitat Pasir Berlumpur dan Lamun di Perairan Teluk Kulisusu kabupaten Muna. Skripsi. Jurusan Perikanan. Fakultas Pertanian. Universitas Haluloeo. Kendari.

Martoyo, J., Aji, N., Winanto, T. (2007). Budidaya Teripang. Penebar Swadaya. Jakarta. 76 hal.

Mongabay. (2013). Situs Berita Lingkungan. Perairan Misool Lestari Warga Desa Folley Diberkahi-Limpahan-PanenHasil-Laut. Diakses Juni 2020. https://www.mongabay.co.id/2013/07/17 
/perairan-misool-lestari-warga-desafolley-diberkahi-limpahan-panen-hasillaut/diakses

Nurafni, Muhammad, S.H., Kurung, N.S. (2020). Pola Sebaran dan Indeks Ekologi Teripang di Perairan Army Dock Desa Pandanga Kabupaten Pulau Morotai. Aurelia Journal Vol. 1 (2) : 121-128

Odum, E.P. (1971). Fundamental of Ecology. 3rd ed. Tokyo: W.B. Saundes Company.

Odum, E.P. (1993). Dasar-dasar Ekologi. Gadjah Mada University Press, Jogjakarta.

Odum, E.P. (1998). Dasar-dasar Ekologi. Gadjah Mada University Press, Jogjakarta.

Pemda Kabupaten Raja Ampat. (2006). Atlas Sumberdaya Pesisir Kabupaten Raja Ampat Provinsi Irian Jaya Barat. Kerjasama Pemerintah Daerah Kabupaten Raja Ampat dan Conservation International Indonesia. 154 hal.

Sabariah, V., Tarukbua, M., Parenden, D. (2009). Kondisi habitat, distribusi dan kelimpahanteripang (Holothuroidea) di pesisir Teluk Doreri Manokwari. Jurnal Perikanan dan Kelautan (7) : 1-8.

Sarmawati, Ramli, M., Ira. (2016). Distribusi dan Kepadatan Teripang (Holothuridea) di Perairan Tanjung Tiram Kecamatan Moramo Utara Kabupaten Konawe Selatan. Jurnal Manajemen Sumber Daya Perairan, 1(2): 183-194.

Solikhatun I., Maridi, S. Budiastuti. (2019). Analisis Vegetasi Penutup Lantai (Lower Crop Community - LCC) di Kawasan Sabuk Hijau Waduk Serbaguna Wonogiri. Seminar Nasional Pendidikan Biologi dan Saintek (SNPBS) ke-IV 2019. Surakarta, 5 Mei 2019. 